- INNOVATIVE IDEA

Volume 9 Issue 22017

DOI: 10.21315/eimj2017.9.2.8

ARTICLE INFO

Submitted: 14-02-2017

Accepted: 25-03-2017

Online: 30-06-2017

\section{Piloting Surgical Near-Peer Microlearning Sessions: Lessons Learnt from Students and Teachers}

\author{
Noor Janjua
}

ENT Department, Queen Alexandra Hospital, Portsmouth Hospital

Trust, UK

To cite this article: Janjua N. Piloting surgical near-peer microlearning sessions: lessons learnt from students and teachers. Education in Medicine Journal. 2017;9(2):65-68. https://doi.org/10.21315/ eimj2017.9.2.8

To link to this article: https://doi.org/10.21315/eimj2017.9.2.8

\title{
ABSTRACT
}

Near-peer microlearning session in surgical topics were piloted, and feedback gathered from students and teachers to advise improvement. Sessions were run fortnightly over three months. Core Surgical Trainees (CSTs) chose topics to teach Foundation Year Doctors (FYDs) and were briefed on the intention of the sessions - 15 minutes teaching with clear learning points. After the pilot, online surveys were completed by students and teachers for feedback. Students found the topics of teaching appealing, while the format was of secondary attraction. The different format was noted by $60 \%$ of students, although $60 \%$ also reported the sessions as lasting 30 minutes -1 hour. Teachers reported being well briefed, but found the format difficult to prepare for. About $66.7 \%$ reported a planned session length of 15 minutes -30 minutes. Obstacles to attendance revolved around difficulties extricating themselves from clinical duties. Students suggested regularity of sessions would help attendance, as would promoting awareness among firms. For teachers, a more structured brief could facilitate building the microlearning session. Future sessions should include knowledge tests to ascertain effectiveness of teaching.

Keywords: Near-peer teaching, Microlearning, Medical education

CORRESPONDING AUTHOR Noor Janjua, MBBCh, MRCS(ENT), ENT Department, Queen Alexandra Hospital, Southwick Hill Road, Cosham, Portsmouth, PO6 3LY | Email: nj238cam@gmail.com

\section{INTRODUCTION}

Peer and near-peer teaching involves teaching by peers within the learner group, or by those slightly senior to the learners. They are well-established, effective teaching methods in medical education, especially within medical schools. Later in training, taking time from clinical duties to both lead and attend teaching sessions becomes more difficult, and the extent of peer or near-peer teaching becomes more variable. However, these teaching methods can be seen to be useful in the post-graduate setting for both learners and teachers (1).
Microlearning is a teaching method which can have varying definitions in different contexts. At its core is the concept of teaching on a small scale, be that in terms of time, content, learners or materials (2). Generally, it involves short teaching sessions, with the intention of delivering a small number of focused teaching points, and often incorporates computer or technologybased learning. This format allows effective teaching to take place within timeconstrained conditions such as the clinical work-place. 
Locally, teaching for the Foundation Years (FY) doctors was taking place for one hour weekly and were mostly of a lecture format. Previous feedback had remarked on a lack of teaching in surgical topics, but the number of one hour sessions available were required to cover the FY curriculum. Pilot sessions of near-peer microlearning in surgical topics were run to establish whether and how these could be a useful addition to the current teaching programme.

\section{METHODS}

Microlearning sessions were intended as 15 minutes of teaching, using any material desired. PowerPoint presentations were discouraged due to being felt inappropriate for the length of time. A maximum of three learning points were suggested. Each session was led by a Core Surgical Trainee who was briefed by email. These teaching trainees were one to two years ahead in their medical training than the FY learners, and worked at the same hospital. The teachers chose the topics to be taught. The author contributed to this teaching, but did not attend or supervise other sessions.

The programme was run fortnightly over three months. A previous programme had found that learners were less likely to attend teaching at the beginning and end of the working week due to clinical workloads often being heavier at these times. Similarly, they were also less likely to attend out-of-hours sessions. The time for the microlearning sessions were therefore booked to avoid these pitfalls and to avoid other teaching sessions.

The exact time and room location for each fortnight's teaching sessions were organised through the local postgraduate foundation programme administrator. Information regarding the sessions was disseminated to the FY doctors via email.

Institutional review for ethical approval was not requested as the sessions and associated feedback were organised as part of the wider in-house post-graduate teaching programme. Participation in both teaching sessions and feedback surveys was entirely voluntary, and the surveys did not collect any identifiable data. The project did not pose any substantial risks to students or teachers.

After the pilot period, two online surveys were distributed; one to the FY doctors and one to the Core Surgical Trainees (CSTs). Part of the FY survey also considered motivations and obstacles of attendance, therefore even those who had not managed to attend were encouraged to complete the first part of the survey in order to assess these issues. Multiple answers could be selected when considering reasons for certain behaviours and preferences.

\section{RESULTS}

Integral to the concept of microlearning, the near-peer taught sessions were held in small groups. Of the nine respondents to the FY learners' survey, six had attended the sessions and three had not. There were four respondents to the CST teachers' survey.

\section{FY Learners}

FY respondents had wanted more surgical teaching and found the topics being covered appealing, with $66.7 \%$ stating these reasons as motivation for attending. The format was of secondary attraction, with $16.7 \%$ choosing the shorter sessions, smaller groups and the CST teachers as the draw.

Clinical duties presented the greatest obstacles to attendance, either in their timing or volume of work $(50 \%-66.7 \%)$. One respondent felt that the topics were not relevant. Interestingly, two respondents felt that an obstacle to attendance was the non-mandatory nature of the sessions. A free text answer suggested that making them compulsory would make the respondent more likely to attend. Other free-text answers proposed logistical changes, making the sessions more regular, with a fixed day, time and location, would also facilitate attendance. 
Positively, $100 \%$ of FY attendees felt they left the teaching sessions with the desired one or two key learning points. The sessions were felt to have a different format to other teaching by $60 \%$ of respondents, although $60 \%$ also reported the sessions as lasting 30 minutes to 1 hour - not quite in keeping with the microlearning concept! (Table 1).

\section{Core Surgical Trainee (CST) Teachers}

CST respondents who taught the sessions were motivated by their enjoyment of teaching, and its usefulness both for their own learning, and in portfolio-building. These reasons were chosen by $100 \%$ of the respondents as encouraging factors for teaching. Only one respondent felt that they had sufficient time available in their work schedule to encourage them to teach. Lack of time for teaching $(75 \%)$, and for preparing sessions $(100 \%)$, were the main obstacles cited. Lack of knowledge was cited by $25 \%$.

All respondents reported being well briefed, but found the format difficult to prepare. Three quarters reported a planned session length of 15 minutes-30 minutes, with the rest planning less than 15 minutes. Respondents stated that at least three days had been given to prepare for the teaching sessions, some had over a week. All CST teachers felt that this was enough time.

When surveyed, a variety of preferences were given for choosing teaching topics (Figure 1). When preparing the sessions, $75 \%$ of teacher respondents adapted previously-used teaching material for these sessions, the rest used new material. Resources used still included PowerPoint presentations, but also paper flipcharts and handouts.

Table 1: FY attendees impressions about the format of teaching

\begin{tabular}{cccc}
$\begin{array}{c}\text { Sessions felt to have } \\
\text { different format? }\end{array}$ & $\begin{array}{c}\text { Percentage of } \\
\text { respondents }\end{array}$ & $\begin{array}{c}\text { Estimated length of } \\
\text { sessions }\end{array}$ & $\begin{array}{c}\text { Percentage of } \\
\text { respondents }\end{array}$ \\
\hline Yes & $60 \%$ & $<15$ minutes & $20 \%$ \\
No & $20 \%$ & $15-30$ minutes & $20 \%$ \\
Some & $20 \%$ & $>30$ minutes & $60 \%$ \\
\hline
\end{tabular}

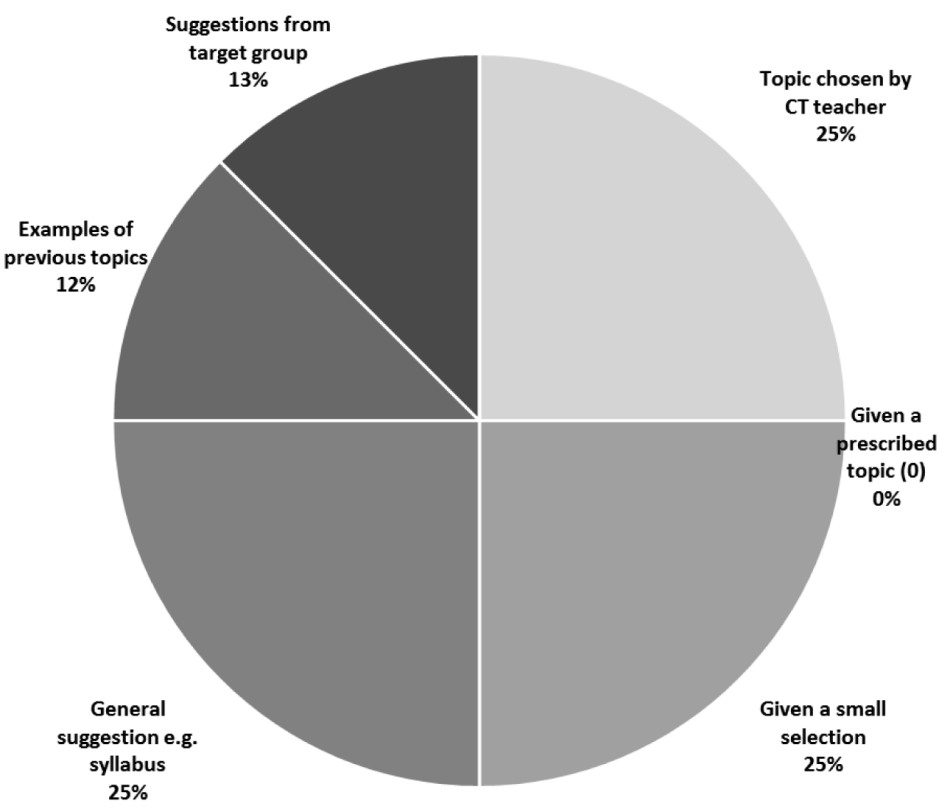

Figure 1: CST's preferred methods of topic selection. 


\section{DISCUSSION}

Although the expectedly small sample size precluded true statistical analysis, this pilot has suggested that near-peer microlearning sessions for surgical teaching are feasible and do engage both CST teachers and FY learners. As a pilot, the project did not directly examine the efficacy of the teaching, but was used to identify practical and logistical issues in running the teaching programme. Appropriate organisation and running of the programme and associated studies is essential before efficacy can be validly assessed.

Such issues to improve upon were identified in these surveys. Most of these related to attendance and preparation of the sessions. FY survey results showed that the FY learners were interested in surgical teaching, regardless of the format, but found it difficult to attend due to the volume of clinical work. Free-text feedback suggested that formalising the time and venue of teaching and holding it on a more frequent, weekly basis, would help facilitate attendance. It was also suggested informing firms of the teaching and even making the sessions mandatory.

The microlearning sessions were piloted as an adjunct to current teaching and as such were deliberately not made mandatory to avoid over-burdening the FY doctors. The feedback suggesting this could be interpreted in at least two ways; FY doctors may feel the extra "draw" of being obliged to attend teaching is necessary for their attendance, or they may feel they would be more able to disengage from non-urgent clinical work if they had the justification of mandatory teaching. One respondent suggested that raising awareness of these sessions among other members of their clinical teams would enable better attendance, indicating that justification to the team is a point that needs addressing.

CST teacher survey feedback suggested that although the microlearning concept was one they felt engaged with, the practicality of preparing a teaching topic was more difficult than initially envisaged. Although briefed for a 10 minutes-15 minutes presentation, most CST teachers reported planning a 15 minutes- -30 minutes session, while FY learners reported most sessions lasting over 30 minutes. If this were the case, the concept of microlearning would be somewhat diluted. When designing the next study, a more structured approach will be needed. This would include the choice of pre-determined topics based on FY requests and the curriculum, and clearer, objective instructions on how to prepare a microlearning session. These changes should make preparation easier for the CST teachers, to deliver true microlearning sessions.

Finally, future programmes and studies should of course continue to gather feedback in a timely manner from both teachers and learners, including assessment of the efficacy of the teaching itself. Nearpeer teaching has been shown to be useful to both teachers and students in providing a mutually beneficial learning and development environment (3). However, literature on its efficacy in medical education is scarce, and even more so for microlearning. The next iteration of this teaching programme should therefore also implement measures to assess the effectiveness of the teaching.

\section{REFERENCES}

1. Khaw C, Raw L. The outcomes and acceptability of near-peer teaching among medical students in clinical skills. Int $\mathrm{J}$ Med Educ. 2016;7:188-94. https://doi. org/10.5116/ijme.5749.7b8b.

2. Nelson AJ, Nelson SV, Linn AMJ, Raw LE, Kildea HB, Tonkin AL. Tomorrow's educators ... today? Implementing near-peer teaching for medical students. Med Teach. 2013;35(2):156-9. https://doi.org/10.3109/0 142159X.2012.737961.

3. Hug $\mathrm{T}$, editor. Didactics of microlearning. Munster:Waxmann Verlag GmbH; 2007. 